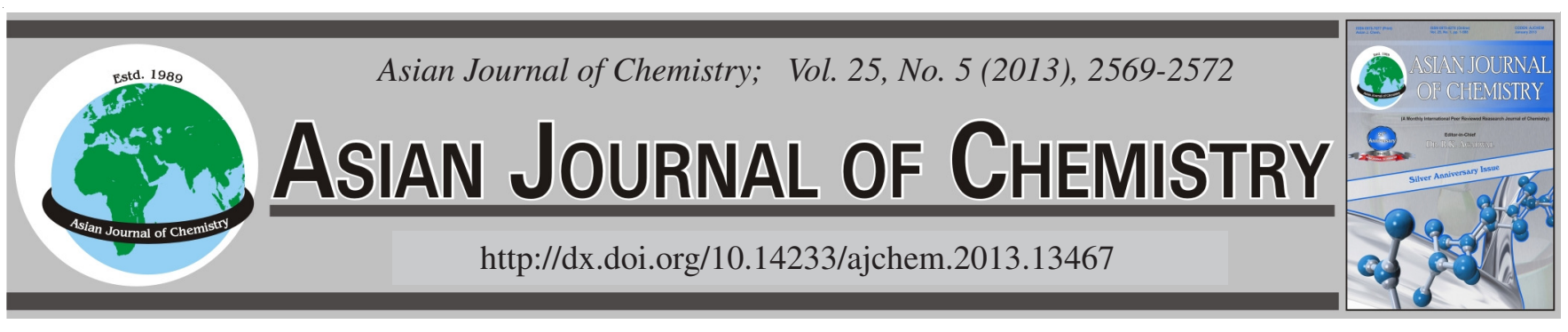

\title{
Evaluation of Fluoride and Hydrogen Ions Concentrations in Commercial Bottled Drinking Water in South Africa
}

\author{
E.D. Dikio*, P.A. Mzulwini, C.W. Dikio and F.M. MtunZI
}

Department of Chemistry, Vaal University of Technology, P.O. Box X021, Vanderbijlpark, South Africa

*Corresponding author: Fax: +27 16950 9794; Tel: +27 16950 9606; E-mail: ezekield@ vut.ac.za

\begin{abstract}
This study was related to determine the fluoride ion contents of bottled drinking water in South Africa by ion chromatography. A number of brands of bottled water with labeled fluoride and hydrogen ion concentrations were analyzed to evaluate the concentration of fluoride and hydrogen ions present in the bottled water. This study found one brand of bottled drinking water to have $119 \%$ more fluoride than indicated on the bottle water label. The lowest amount of fluoride measured was $26.35 \%$ less fluoride than recorded on the bottle water label. $\mathrm{pH}$ of water indicated on different brands of bottled drinking water also varied between brands. One brand of drinking water was found to have a $\mathrm{pH}$ that is $42 \%$ more than indicated on the label of the brand.
\end{abstract}

Key Words: Ion chromatography, Fluoride, Bottled water, pH.

ᄂ - - - - - - - - - - - - - - - - - - - - - - - - - - - - -

\section{INTRODUCTION}

Water is an essential natural resource for sustaining life and environment that was always thought to be available in abundance and free gift of nature ${ }^{1-4}$. Presence of various hazardous contaminants like fluorides in underground water has been reported from different parts of India ${ }^{3}$. In many cases, the water sources have been rendered unsafe not only for human consumption but also for other activities such as irrigation and industrial needs ${ }^{1,2}$.

Fluoride is a ubiquitous element present in soil and water in low concentrations. Fluoride exposure via drinking water is an endemic problem in several parts of the world such as China, India and Mexico ${ }^{3-5}$. In groundwater, natural fluoride concentrations range from trace quantities to over $25 \mathrm{mg} / \mathrm{L}$. When fluoride is ingested by humans and other animals some is taken up by body tissues, with long term deposition in teeth and bones ${ }^{3}$. Fluoride is an essential microelement for which small amounts, in the order of $1 \mathrm{mg} / \mathrm{L}$ ingested in water, are generally conceded to have a beneficial effect on the rate of occurrence of dental caries, particularly among children. On the other hand, excessive intake of fluoride results in pathological changes in teeth or dental fluorosis and skeletal fluorosis. Fluorosis is an endemic disease resulting from excess intake of fluoride either through drinking water, food or dentifrices at concentration of $2.0 \mathrm{mg} / \mathrm{L}$ or above. Fluoride can rapidly cross the cell membrane and is distributed in skeletal and cardiac muscle such as the liver, skin and erythrocytes ${ }^{4-10}$. On the other hand, due to its strong electronegativity, fluoride is attracted by positively charged calcium ions in teeth and bones. According to world health organization ${ }^{11}$ permissible limit for fluoride in drinking water is $1.5 \mathrm{mg} / \mathrm{L}$. The United State Public Health Service has set a range of allowable concentrations for fluoride in drinking water for a region depending on its climate conditions because the amount of water consumed and consequently the amount of fluoride ingested being influenced primarily by the air temperature ${ }^{5-8}$.

Ion chromatography offers an alternative method to determine various ions like fluoride in short time and low effort. The determination can be performed using single column ion chromatography and two different columns ion chromatography for cations and anions ${ }^{12-15}$. Regulations of the South African health ministry concerning natural mineral waters, spring waters and table waters oblige manufacturers to display the precise level of fluoride ion content in the product.

Many bottled water produced in the Republic of South Africa for public consumption show on their labels the fluoride content of the water. Some bottled water sold were without any indication of their fluoride content. In this study, we aim to determine if the fluoride ion concentration on the label of some bottled water sold to the public is a true representation of the concentration of fluoride ion on their label. Will the fluoride ion concentration on the label of the bottled water be above or below the recommended limit of fluoride ion? Bottled water for fluoride analysis have been randomly selected, bottles with fluoride and $\mathrm{pH}$ level indication have been selected to 
represent an array of bottled water sold to the public in the Republic of South Africa.

\section{EXPERIMENTAL}

Ten brands of commercial bottled drinking water used in this study were obtained locally in South Africa. Fluoride standard solutions for ion chromatography were prepared by a serial dilution of $1000 \mathrm{ppm}$ (part per million) sodium fluoride stock. The stock solution was prepared by dissolving 0.0221 $\mathrm{g}$ of $\mathrm{NaF}$ in $1 \mathrm{~L}$ of solvent. All chemicals used for analysis were analytical grade reagents. Double distilled and deionized water were used for all experiments.

$\mathrm{pH}$ measurements were taken with a Adwa AD8000 professional multi-parameter-pH-ORT-conductivity-TDS-TEMP bench meter with a $\mathrm{pH}$ range of 0.00 to 14.00 and a resolution of $0.001 \mathrm{pH}$. The accuracy of the $\mathrm{pH}$ meter is \pm 0.002 at $20^{\circ} \mathrm{C}$. Ion chromatography was performed on a Dionex ICS 1000 ion chromatography equipped with electrically actuated polyether ether ketone (PEEK) and digital conductivity detector, DS6 heated conductivity cell housed in an electrochemical conductivity detection unit (ECD, ASRS $4 \mathrm{~mm}$ ). The ion chromatography is supplied with autosampler AS40 and software. The columns used were: (1) Cation trap column CS12A high efficiency cation-exchange resin in the hydronium form, $(4 \times$ $250 \mathrm{~mm}$ ) analytical. (2) Dionex IonPac CG12A guard column $(4 \times 50 \mathrm{~mm})$. (3) Anion column, Dionex IonPac AS22 $(4 \times$ $250 \mathrm{~mm}$ ) column. (4) Dionex IonPac AG22 guard column $(4 \times$ $50 \mathrm{~mm}$ ). The columns were used with a Dionex cation self regenerating suppressor (SRS) (4 mm).

Calibration: The eluent reservoir of the ion chromatography was set and the pump primed. The operational conditions were set at $12.5 \mathrm{~min}$, run time and a flow rate of $1.2 \mathrm{~mL} / \mathrm{min}$. The ion chromatography was then equilibrated and operational status verified. Standards in the concentration range of 0.1 to $0.8 \mathrm{mg} / \mathrm{L}$, prepared from fluoride $1000 \mathrm{mg} / \mathrm{L}$ standard were injected by an auto-sampler through a vial. Anion eluent, AS22 eluent concentration in deionized water. Final concentration after 100 dilutions, water $94.0 \%, 4.5 \mathrm{mM}$ sodium carbonate $4.8 \%$ and $1.4 \mathrm{mM}$ sodium carbonate $1.2 \%$. Cattion eluent, $\mathrm{CS} 12 \mathrm{~A}$ eluent concentration in deionized water. Final concentration after 20 dilutions, methanesulphonic acid $2.6 \%$ and water $97.4 \%$ and ultrapure water $18 \mathrm{M} \Omega$.

Sampling: Bottled water for fluoride and $\mathrm{pH}$ analysis were selected from bottled water brands with fluoride and $\mathrm{pH}$ level indicated on their labels sold to the public in the Republic of South Africa. Ten brands of bottled water were selected. For each selected bottled water brand, samples were purchased from different retail outlets in three South African provinces, namely: north west, Gauteng and free state provinces. Brand samples were purchased on the first week of every month in three consecutive months to ensure that bottle water brand samples were from different production batches and from different manufactured dates. All three bottled water for each brand sample were then mixed and homogenized in a 21 flask then analyzed for $\mathrm{pH}$ and fluoride ion concentrations. To conceal the identity of the manufacturer, selected bottled water samples have been given arbitrary numbers from 1 to 10 .

Procedure: Analysis of fluoride in commercial bottled water were based on the procedure for fluoride analysis in water described by Neele et al. ${ }^{2,16}$. Fluoride and $\mathrm{pH}$ measurements were made in triplicates and the average values calculated.

\section{RESULTS AND DISCUSSION}

Calibration curves covering the concentration range shown in Fig. 1 were drawn and injected into the ion chromatography in $50 \mu \mathrm{L}$ aliquots. Linear relationships between peaks areas and concentration were experimentally verified. The calibration was made between peak height and concentration because the correlation coefficient was higher than using peak. The calibration data in Fig. 1 illustrate good correlation coefficient.

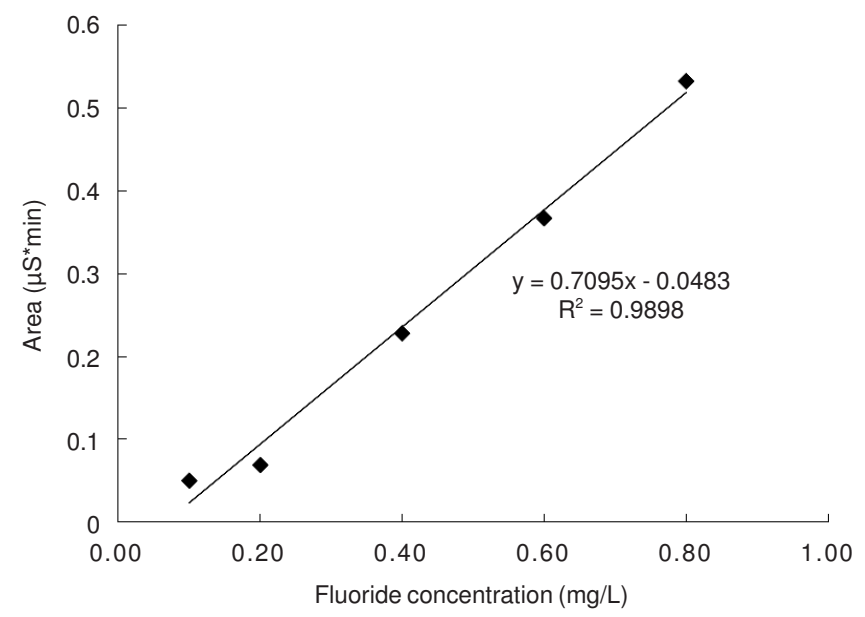

Fig. 1. Standard concentration range, regression equation of the fluoride ion calibration plots, peak signal $(\mathrm{y}, \mu \mathrm{S} / \mathrm{min}) v s$. concentration $(\mathrm{x}, \mathrm{mg} / \mathrm{L})$ and coefficient of correlation $\left(\mathrm{R}^{2}\right)$

Fluoride concentrations on the label of 10 locally produced and marketed bottled water in the republic of South Africa are presented on Table-1. The fluoride ion concentrations on the labels of the bottles indicate a concentration range from $0.01-0.5 \mathrm{mg} / \mathrm{L}$. These fluoride ion concentrations are well within the concentration limits accepted for consumption and daily intake. World health organization (WHO) expert committee suggests a level of fluoride from $0.5-1.0 \mathrm{mg} / \mathrm{L}$ 10. Ion chromatographic analysis of fluoride ion concentration in the bottled water samples show fluoride ion concentration in the bottled water ranging from $0.05-0.6755 \mathrm{mg} / \mathrm{L}$ (Fig. 2).

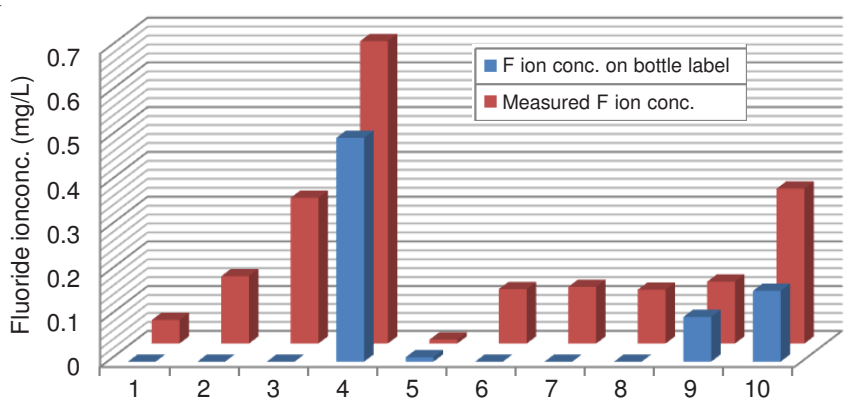

Fig. 2. A comparison of fluoride concentration provided on the label of water bottle samples and fluoride concentration determined using ion chromatography

Fluoride ion concentration measured and fluoride ion concentration displayed on sample bottles by the manufacturer 
did not match except in sample 5, Table-1, where the fluoride ion concentration displayed on the bottle is $0.01 \mathrm{mg} / \mathrm{L}$ and that determined by ion chromatography is $0.0087 \mathrm{mg} / \mathrm{L}$. Fluoride ion concentration on all other samples were either above or below the concentration of fluoride ion displayed on the bottled water sample by the manufacturer.

\begin{tabular}{ccc}
\hline \multicolumn{3}{c}{ TABLE-1 } \\
\multicolumn{3}{c}{$\begin{array}{c}\text { FLUORIDE ION CONCENTRATIONS FROM SAMPLE LABEL } \\
\text { AND ION CHROMATOGRAPHIC ANALYSIS }\end{array}$} \\
\hline Sample & $\begin{array}{c}\text { Manufacturer's fluoride } \\
\text { concentration }(\mathrm{mg} / \mathrm{L})\end{array}$ & $\begin{array}{c}\text { Ion chromatography } \\
\text { results }(\mathrm{mg} / \mathrm{L})\end{array}$ \\
\hline 1 & $\leq 0.2$ & 0.0527 \\
2 & $\leq 0.1$ & 0.1505 \\
3 & $\leq 0.2$ & 0.3256 \\
4 & 0.5 & 0.6755 \\
5 & 0.01 & 0.0087 \\
6 & $\leq 0.2$ & 0.1218 \\
7 & $\leq 0.1$ & 0.1268 \\
8 & $\leq 0.1$ & 0.1202 \\
9 & 0.1 & 0.1383 \\
10 & 0.158 & 0.3461 \\
\hline
\end{tabular}

Highest percentage differences in fluoride ion concentrations (Fig. 3), were found in seven samples ranging from 26 to $119 \%$. Although the fluoride ion concentration on the label of bottled water and that determined by ion chromatography are within $\mathrm{WHO}^{11}$ recommended daily intake and limits, the difference in fluoride ion concentration on the label and that determined by ion chromatography, was highest in sample 10, $119 \%$ more fluoride than that displayed on bottle label. Lowest levels of fluoride ion concentration were found on 3 samples ranging from 26 to $87 \%$ less fluoride ion concentration than that displayed on the label of the bottles.

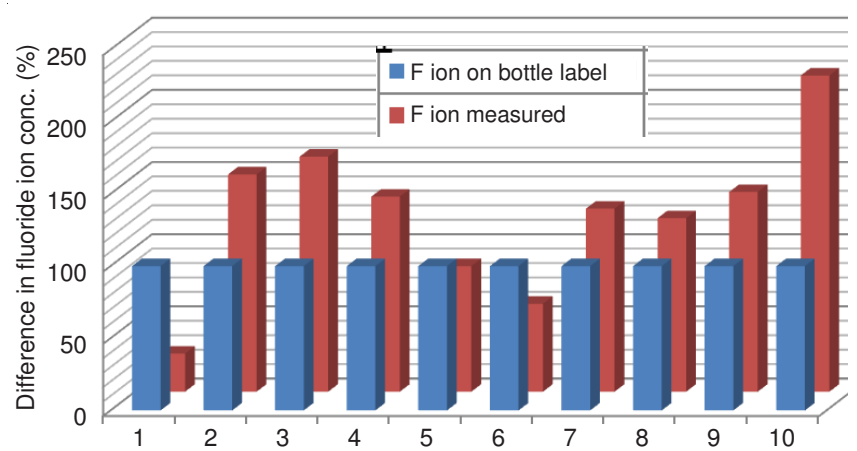

Fig. 3. Percentage difference in the concentration of fluoride ion concentration in bottled water samples

$\mathrm{pH}$ is a measure of the intensity of acidity or alkalinity and the concentration of hydrogen ion in water. $\mathrm{pH}$ values below 4 produces an acidic or sour taste while a $\mathrm{pH}$ value higher than 8.5 produces an alkaline taste ${ }^{17}$. The $\mathrm{pH}$ of water is also a measure of the acid-base equilibrium of water. Table2 presents the $\mathrm{pH}$ values on the label of bottled water samples and their measured $\mathrm{pH}$ values. $\mathrm{pH}$ values displayed on the water bottles ranged from 4.5 to 7.6. It is known that $\mathrm{pH}$ has no direct impact on drinking water, nevertheless, it is an important quality parameter and an important factor in determining the corrosivity of water. Drinking water with a $\mathrm{pH}$ less than 4 will be corrosive while a $\mathrm{pH}$ more than 8 will be too alkaline. $\mathrm{pH}$ values indicated on the water bottle brands show sample No. 8 to have the lowest $\mathrm{pH}$ value of 4.5 while brand No. 9 have the a $\mathrm{pH}$ of 7.6. $\mathrm{pH}$ measurement of all brands show No. 3 and 8 to have lowest $\mathrm{pH}$ values while brand No. 2 gave the highest $\mathrm{pH}$ value of 8.017 (Figs. 4 and 5).

\begin{tabular}{|c|c|c|}
\hline \multicolumn{3}{|c|}{$\begin{array}{c}\text { TABLE-2 } \\
\text { COMPARISON OF MANUFACTURER'S pH PROVIDED ON } \\
\text { SAMPLES LABELS AND MEASURED pH }\end{array}$} \\
\hline Sample & Manufacturer's pH & Measured pH \\
\hline 1 & 7.2 & 7.164 \\
\hline 2 & 5.62 & 8.017 \\
\hline 3 & 5.1 & 4.262 \\
\hline 4 & 6.54 & 7.129 \\
\hline 5 & 7.1 & 7.762 \\
\hline 6 & 6.7 & 5.086 \\
\hline 7 & 5.2 & 5.003 \\
\hline 8 & 4.5 & 4.663 \\
\hline 9 & 7.6 & 7.721 \\
\hline 10 & 7.0 & 7.762 \\
\hline
\end{tabular}

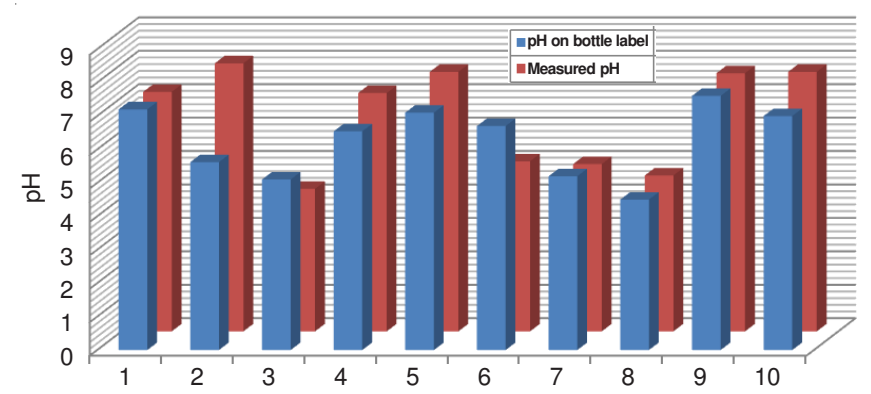

Fig. 4. Graphical presentation of the $\mathrm{pH}$ on the bottle labels and the measured $\mathrm{pH}$

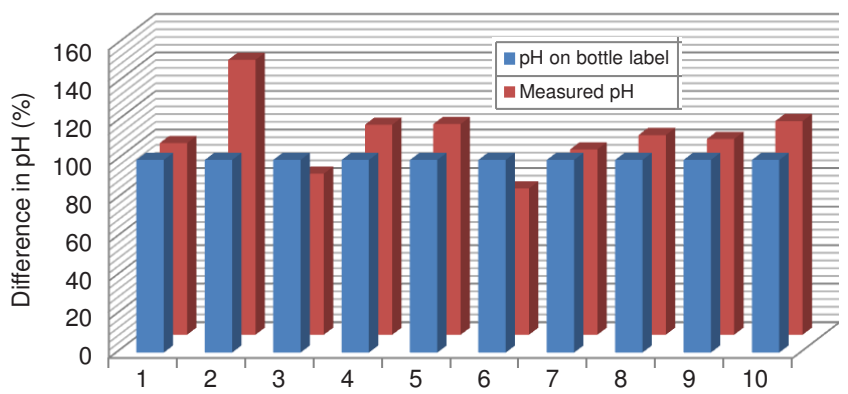

Fig. 5. Percentage difference in the $\mathrm{pH}$ on bottle label compared to measured $\mathrm{pH}$

A comparison of the percentage difference between $\mathrm{pH}$ values indicated on sample bottles and measured $\mathrm{pH}$ values show samples No. 6 to have a $\mathrm{pH}$ value lower than that indicated on the bottle. While in sample No. 2, measured $\mathrm{pH}$ of this water is $42 \%$ higher than indicated on the bottle.

\section{Conclusion}

Fluoride ion concentrations of bottled drinking water in the Republic of South Africa were found to vary widely. Fluoride ion indicated on different bottled drinking water also varied from one brand to another. This study found one brand of bottled drinking water to have $119 \%$ more fluoride than indicated on the bottle water label. The lowest amount of fluoride measured was $26.35 \%$ less fluoride than recorded on 
the bottle water label. $\mathrm{pH}$ of water indicated on different brands of bottled drinking water also varied between brands. One brand of drinking water was found to have a $\mathrm{pH}$ that is $42 \%$ more than indicated on the label of the brand. These values bring light the unreliability in the fluoride ion and $\mathrm{pH}$ values indicated on the labels of bottled drinking water found in South Africa.

\section{ACKNOWLEDGEMENTS}

This work was supported by a research grant from the Faculty of Applied and Computer Science Research and Publications Committee of Vaal University of Technology, Vanderbijlpark, South Africa.

\section{REFERENCES}

1. R.C.M. Meenakshi, J. Harzard. Mater, 137, 456 (2006).

2. E.D. Dikio, Res. J. Appl. Sci. Eng. Technol., 2, 574 (2010).

3. B. Singh, S. Gaur and V.K. Garg, J. Harzard. Mater., 144, 147 (2007).

4. J.C. Roos and A.J.H. Pieterse, Hydrobiologia, 306, 41 (1995).

5. A. Ruiz-Payan, M. Ortiz and M. Duarte-Gardea, Microchem. J., 81, 19 (2005).
6. P.T.C. Harrison, J. Fluorine Chem., 126, 1448 (2005).

7. W. Czarnowski, K. Wrzesniowska and J. Krechniak, Sci. Total Environ., 191, 177 (1996).

8. C.S. Sundaram, N. Viswanathan and S. Meenakshi, J. Harzard. Mater., 163, 618 (2009).

9. K.W.M. Msonda, W.R.L. Masamba and E. Fabiano, Phys. Chem. Earth, 32, 1178 (2007).

10. C. Neal, M. Neal, H. Davies and J. Smith, Sci. Total Environ., 314316, 209 (2003).

11. World Health Organization: Expert Committee on Oral Health and Fluoride Use. Fluorides and Oral Health (1994).

12. M.S. Yadawe, S.M.T.D.M. Hiremath and S.A. Patil, E.J. Chem., 7, 641 (2010).

13. M.E. Fernandez-Boy, F. Cabrera and F. Moreno, J. Chromatogr. A., 823, 285 (1998).

14. M. El-Said, M. Ramzi and T. Abdel-Moghny, Desalination, 249, 748 (2009).

15. J. Opydo-Szymaczek and J. Opydo, Res. Report Fluoride, 42, 233 (2009).

16. J. Neele, W.A. van den Beld and R.F.M.J. Cleven, A Sensitive and Selective Ion Chromatographic Method for the Determination of Fluorides in Rain Water Report No. 502501004, February (1995).

17. V.T. Patil and P.R. Patil, E.J. Chem., 8, 53 (2011). 